\title{
Análise crítica da aplicação do custeio-meta no desenvolvimento de empreendimentos de habitação de interesse social
}

\author{
A critical analysis of the application of target costing in \\ the development of social housing projects
}

\section{Ana Mitsuko Jacomit Ariovaldo Denis Granja}

\section{Resumo}

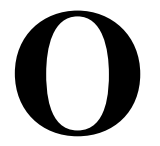

custeio-meta é uma abordagem amplamente aplicada na manufatura e representa uma inovação no processo de desenvolvimento de produtos, em que o custo, a qualidade e a funcionalidade não são conseqüências do processo de projeto, mas parâmetros de entrada.

Este artigo investiga a aplicabilidade da abordagem custeio-meta no desenvolvimento de empreendimentos habitacionais de interesse social (EHIS). Tais empreendimentos possuem muitas peculiaridades em relação a produtos da manufatura, não havendo evidências de que esta abordagem seja adequada ao desenvolvimento de EHIS, nem mesmo de produtos da construção civil em geral. Este artigo se propõe a investigar como e por que algumas características dos EHIS - a maioria delas comuns também a outros tipos de empreendimentos de construção - influenciam a aplicabilidade do custeio-meta. Estas questões foram analisadas com base na adaptação de conceitos da manufatura para a construção civil e num estudo de caso exploratório conduzido em uma companhia estadual de provisão habitacional. $\mathrm{O}$ estudo propõe adaptar o custeio-meta às condições do contexto de análise, concentrar esforços nas atividades mais vantajosas ou ajustar o contexto de análise de modo a maximizar os seus benefícios e minimizar incertezas.

Palavras-chave: Custeio-meta. Custo-meta. Desenvolvimento de produto. Habitação social. Gestão de custos.

Ana Mitsuko Jacomit Programa de Pós-graduação em Engenharia Civil Universidade Estadual de Campinas

Campinas - SP - Brasil Caixa Postal 6021 CEP 13083-852

Tel.: (19) 3521-2082

E-mail: anamjacomit@gmail.com

Ariovaldo Denis Granja Programa de Pós-graduação em Engenharia Civil

Universidade Estadual de Campinas

E-mail: adgranja@fec.unicamp.br

Recebido em 09/10/09 Aceito em 23/12/09

\begin{abstract}
Target costing is an approach widely used in manufacturing and represents an innovation in the product development process, in which cost, quality and functionality are not merely outcomes of the design process, but input parameters. This paper investigates the applicability of target costing in the development of social housing projects (SHP). Such projects have many peculiarities in relation to manufacturing and there is no evidence that this approach is suitable for the development of SHP, or even building projects in general. This paper aims to investigate how and why certain features of SHP - most of them also common in other types of construction projects influence the applicability of target costing. These questions were analyzed based on the adaptation of concepts from manufacturing to construction and on an exploratory case study conducted in a public housing company. The study suggests to adapt target costing to this context, to concentrate on the most beneficial activities, or to adjust the context in order to maximize the benefits and minimize.
\end{abstract}

Keywords: Target costing. Target-cost. Product development. Social housing. Cost management. 


\section{Introdução}

O déficit habitacional brasileiro é de cerca de 6,273 milhões de habitações ${ }^{1}$, para uma população de cerca de 192 milhões de habitantes ${ }^{2}$. Com o crescimento demográfico positivo, esse número tende a aumentar, elevando também a solicitação sobre os órgãos públicos para a construção de novas casas populares. Dessa forma, o foco das políticas públicas habitacionais é normalmente voltado para a maximização do número de unidades habitacionais construídas, atribuindo priorização secundária a fatores como a qualidade do produto entregue à população e o preenchimento de seus requisitos. De fato, quando se tem um montante determinado para a execução de uma unidade habitacional, quanto menos se gastar em cada uma delas, mais unidades habitacionais poderão ser construídas. Entretanto, postula-se a questão: o montante que está sendo gasto em cada unidade habitacional está de acordo com os padrões de qualidade dos EHIS entregues? Ou seja, não seria possível entregar moradias com mais qualidade e com mais valor agregado pelo mesmo custo ou menos? $?^{3}$

A resposta a essa questão depende das capacidades produtivas de cada empresa e das peculiaridades de cada empreendimento, entre outros fatores, mas passa inevitavelmente pela definição dos termos empregados - qualidade e valor. O termo "qualidade" pode ser empregado com uma infinidade de significados, do simples atendimento às especificações até a capacidade de entusiasmar o cliente, passando pela maximização do valor para o cliente (PICCHI, 1993). O conceito de valor também é bastante amplo e sua definição envolve fatores subjetivos, como discutidos por Miron (2008). Uma das questões principais ao se tratar do conceito de valor é a definição do interlocutor. Sob a perspectiva do produtor, o valor é uma proporção entre a funcionalidade adicionada ao produto e seu custo, ou seja, o valor para o produtor é a relação entre a função e o custo (COOPER; SLAGMULDER, 1997; DELL'ISOLLA, 1997). Entretanto, um incremento de valor para o produtor só se transformará em valor para o cliente se a funcionalidade adicionada for interpretada como um benefício e se ela não acarretar aumento no preço superior ao que o cliente espera pagar

\footnotetext{
${ }^{1}$ Contagem efetuada pelo Ministério das Cidades, com base em dados de 2007 da Fundação João Pinheiro, de Belo Horizonte (MG).

${ }^{2}$ População estimada pelo site do Instituto Brasileiro de Geografia e Estatística (IBGE) em 3 de setembro de 2009. Disponível em <http: //www.ibge.gov.br/>.

${ }^{3}$ Segundo dados de 2003, fornecidos pela companhia estudada, os custos diretos para a construção de cada unidade habitacional vertical (apartamento) em municípios do interior giram em torno de R\$ 28 mil a 35 mil.
}

pelo benefício (valor para o cliente = benefícios/preço) (COOPER; SLAGMULDER, 1997). Assim, as dimensões envolvidas na questão levantada anteriormente são: custo/preço, funcionalidade e qualidade.

Sabendo-se que alterações em uma das dimensões irão influenciar as outras duas, o desafio então seria encontrar soluções que proporcionem o aumento da qualidade e da funcionalidade, sem o aumento do custo total. Se essa análise for feita de forma reativa, após a elaboração do projeto, com boa parte dos custos já comprometidos, ela dificilmente retornará resultados satisfatórios. Entretanto, uma abordagem proativa de desenvolvimento de produto ${ }^{4}$ como o custeio-meta pode proporcionar chances maiores de se conseguir sucesso. Com essa abordagem, os níveis de funcionalidade e qualidade do produto, assim como seu custo permissível, seriam definidos na etapa de concepção do empreendimento, passando a ser consideradas entradas para o processo de projeto, ao invés de saídas. Produtos que não atendessem aos padrões predeterminados não seriam liberados para a produção.

Mas como saber se, no contexto de EHIS, a abordagem custeio-meta poderia proporcionar os mesmos benefícios que aqueles provenientes de uma aplicação bem-sucedida na manufatura? Mesmo em empresas da manufatura pode haver diferenças substanciais entre as abordagens adotadas (COOPER; SLAGMULDER, 1997). É fato que a construção civil (CC) possui muitas peculiaridades, assim como o processo de desenvolvimento de EHIS, que podem também interferir numa aplicação de custeio-meta, como a existência de processo licitatório para a execução da obra e a terceirização do processo de projeto. Porém, questiona-se: qual seria a real interferência dessas características numa possível aplicação de custeio-meta no desenvolvimento de EHIS?

Dessa forma, este artigo se propõe a investigar como e por que algumas características dos EHIS a maioria delas comuns também a muitos empreendimentos do subsetor de edificações e da construção civil como um todo - influenciam a aplicabilidade do custeio-meta. Essa questão será analisada neste artigo com base na adaptação de conceitos da manufatura para a CC e num estudo de caso exploratório conduzido em uma companhia estadual de provisão habitacional com atuação no Estado de São Paulo.

\footnotetext{
${ }^{4}$ Como o custeio-meta é uma abordagem ao processo de desenvolvimento de produto (PDP). Não é possível isolar o custeio-meta da gestão do PDP.
} 
Nas próximas sessões, é apresentada uma breve revisão da literatura sobre os conceitos fundamentais relacionados à abordagem custeiometa, assim como a descrição de como a abordagem é integrada ao PDP. Posteriormente, são detalhados os fatores que influenciam a aplicação de custeio-meta segundo Cooper e Slagmulder (1997), seguidos da descrição do método de pesquisa e do PDP em EHIS. Em seguida, são expostas inferências sobre quais características influenciam a aplicabilidade do custeio-meta e como e por que as mesmas interferem no contexto analisado. Por fim, seguemse as conclusões e recomendações para a continuidade desta pesquisa.

\section{Abordagem custeio-meta}

Apesar de ser, em sua essência, uma técnica para gerenciar lucros (MONDEN, 1995), o custeiometa basicamente se constitui numa nova maneira de desenvolver produtos, partindo da definição do custo-meta e dos padrões de funcionalidade e qualidade para o novo produto (MICHAELS; WOOD, 1989; COOPER; SLAGMULDER, 1997; NICOLINI et al., 2000). Neste trabalho, adotou-se a definição de Rozenfeld et al. (2006) para o PDP, que consiste em um conjunto de atividades por meio das quais se busca - a partir das necessidades do mercado e das possibilidades e restrições tecnológicas, considerando as estratégias competitivas e de produto da empresa - chegar às especificações de projeto de um produto e de seu processo de produção, para que a manufatura seja capaz de produzi-lo.

Para muitos autores, as origens da abordagem custeio-meta estão fortemente ligadas ao desenvolvimento da indústria automobilística japonesa no início da década de 1960 (MONDEN, 1995; NICOLINI et al., 2000; YOOK; KIM; YOSHIKAWA, 2005; OKANO; SUZUKI, 2007). O custeio-meta é também a base da estratégia de gerenciamento de custos japonesa para competir globalmente (MONDEN; SAKURAI; 1989) e uma das estratégias de empresas que adotam a mentalidade enxuta (COOPER; SLAGMULDER, 1997). Entretanto, alguns conceitos fundamentais ${ }^{5}$ do custeio-meta - como as análises de alternativas técnicas para atingir um custo-meta predeterminado - já eram utilizados no início do século XX pela Ford, nos Estados Unidos, no desenvolvimento do modelo $\mathrm{T}$ (COOPER; SLAGMULDER, 1997; FEIL; YOOK; KIM, 2004). Também há evidências de aplicação desses conceitos no desenvolvimento do Volkswagen Beetle, na Alemanha, nos anos 1930 (FEIL; YOOK; KIM, 2004). Assim, observa-se que corporações japonesas importaram conceitos ocidentais que vieram a se tornar as raízes da estratégia custeio-meta adotada hoje (MONDEN; SAKURAI; 1989), da mesma forma como adotaram a estratégia de Deming para gestão da qualidade e a desenvolveram para o Controle Total da Qualidade adotado hoje maciçamente por empresas japonesas (PICCHI, 1993).

Mas os conceitos fundamentais do custeio-meta evoluíram nos EUA para outra teoria conhecida como design to a cost, que neste artigo é traduzido como "projetar para um custo". Essa teoria foi desenvolvida para atender aos propósitos da indústria militar americana a partir dos anos 1960 (MICHAELS; WOOD, 1989; MORRIS, 1994). Os fundamentos dessa teoria são basicamente os mesmos do custeio-meta japonês, como mostrado na Figura 1, mas possuem algumas diferenças. Enquanto o custeio-meta apresenta uma destacada orientação mercadológica, com a definição do custo permissível a partir do preço de mercado, a teoria americana foca nos custos ao longo do ciclo de vida. Evidentemente essa diferença de foco se deve aos diferentes contextos nos quais as duas teorias foram desenvolvidas: o custeio-meta foi desenvolvido para o gerenciamento de lucros em mercados competitivos; já a teoria americana foi desenvolvida para reduzir os custos de manutenção e operação dos armamentos para o governo. Há ainda autores que parecem adotar as duas estratégias de forma combinada, como Ballard e Reiser (2004), que utilizam uma estratégia denominada por eles próprios de "projetar para o custo-meta" (design to target cost) no desenvolvimento de empreendimentos de construção. Os empreendimentos nos quais Ballard e Reiser (2004) aplicaram custeio-meta pertencem a um contexto em que o cliente era o único com interesse nos custos ao longo do ciclo de vida - um contexto que se assemelha ao da estratégia "projetar para um custo".

\footnotetext{
${ }^{5}$ Neste artigo, adota-se a definição de Novac e Cañas (2008) para a palavra conceito. Esses autores a definem de uma forma bastante ampla, não fazendo diferenciação entre constructos, variáveis ou processos, mesmo porque não faz parte do escopo deste artigo hierarquizar os conceitos envolvidos. Dessa forma, neste trabalho, onde se lê "conceitos fundamentais do custeio meta", entenda-se "constructos, variáveis ou processos que têm de estar presentes numa aplicação de custeio-meta".
} 


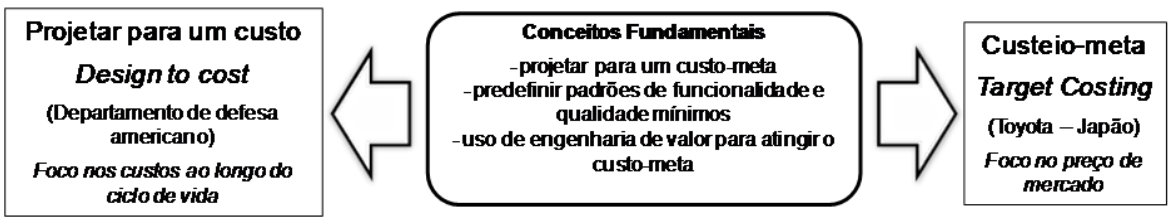

Figura 1 - Conceitos fundamentais do custeio-meta e as suas duas versões encontradas na literatura

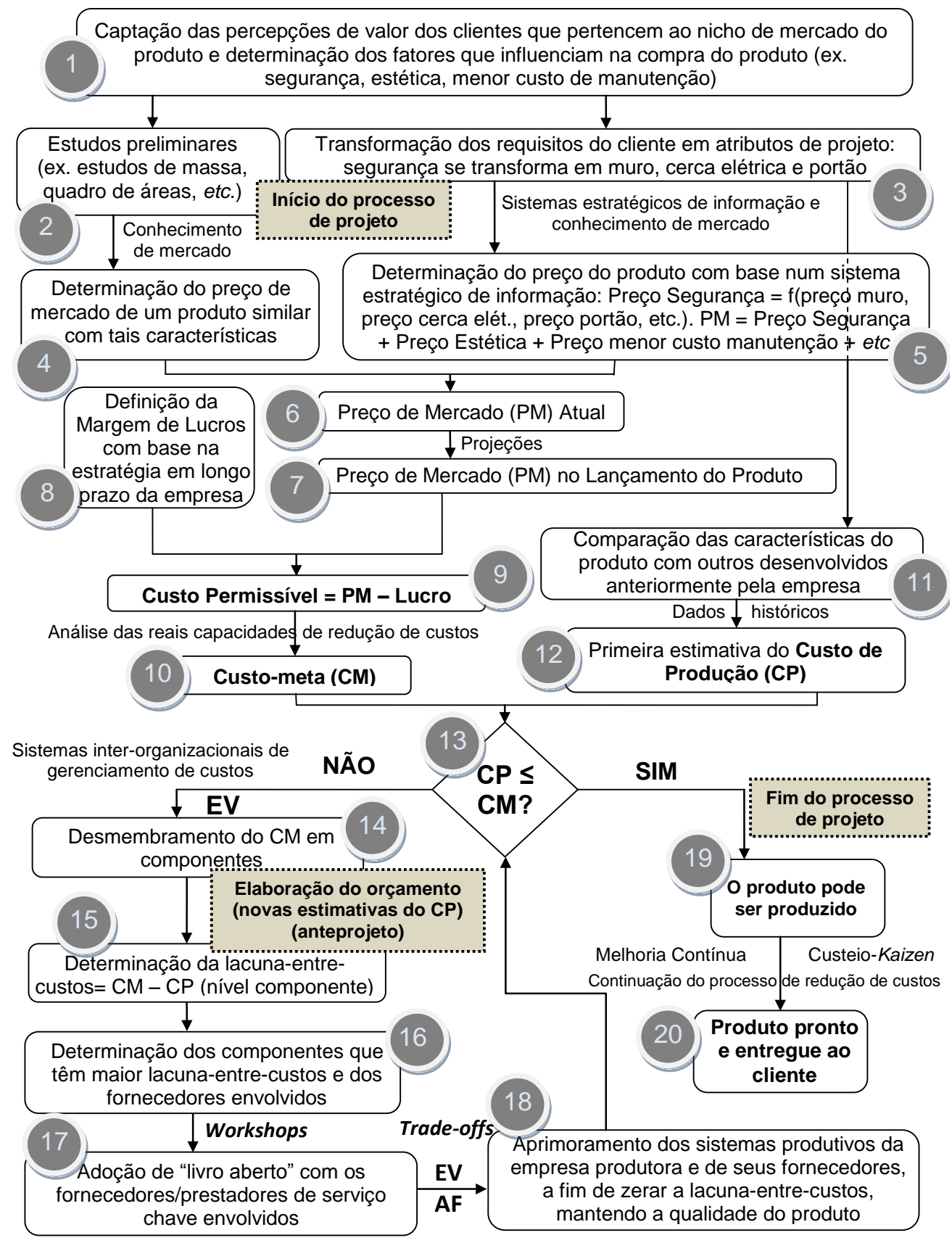

Fonte: Adaptado de Jacomit, Granja e Picchi (2007)

Obs.: itens numerados para referenciar comentários a seguir, no próprio texto.

Figura 2 - Fluxograma de processo produtivo com a aplicação de custeio-meta 
Mesmo considerando somente a teoria referente ao custeio-meta, pode-se encontrar definições diferentes para os termos mais básicos, como o custo-meta. Para Monden (1995), Ansari, Bell e Swenson (2006) e Ellram (2006), o custo-meta de cada produto é determinado com base na diferença entre o preço de mercado e o lucro planejado. Para Cooper e Slagmulder (1997), Ballard e Reiser (2004), Dekker e Smidt (2003) e Nicolini et al. (2000), essa é a definição do custo permissível. O custo-meta seria determinado com base nas capacidades produtivas e de redução de custos da equipe de engenharia e produção, e no custo permissível. Então, o custo-meta representaria um valor intermediário entre o custo de produção estimado e o custo permissível (FEIL; YOOK; KIM, 2004). Em função das diferentes abordagens encontradas na literatura, é adotada como referência neste trabalho a abordagem sintetizada na Figura 2, adaptada de Jacomit, Granja e Picchi (2007), para incluir o conceito de custo permissível (item 9) e indicar em que estágio inicia-se e termina o processo de projeto e de orçamentação.

Antes de detalhar a aplicação do custeio-meta no PDP, é preciso introduzir o conceito do "tripé de sobrevivência”. Segundo Cooper e Slagmulder (1997), um produto é constituído por três dimensões: preço/custo, qualidade e funcionalidade. Sabendo-se que essas dimensões são interdependentes, uma empresa, ao desenvolver um produto, deve balanceá-las, de modo que seu produto atenda às expectativas de seus clientes sem inviabilizar sua produção. Para ajudar nesse balanceamento, Cooper e Slagmulder (1997, 1999) introduzem o conceito do tripé de sobrevivência (survival triplet), mostrado na Figura 3a. De acordo com a teoria proposta por esses autores, um produto só se mostrará rentável se estiver dentro de sua zona de sobrevivência (Figura 3b).

$\mathrm{Na}$ manufatura, como mostra o Quadro 1, os valores máximos de funcionalidade e qualidade são definidos pelo valor mais alto para cada característica que a empresa pode suportar sem comprometer as outras características. Por exemplo, o número exagerado de funções em um produto como uma máquina fotográfica pode comprometer sua qualidade e inviabilizá-la economicamente. Os valores mínimos de funcionalidade e qualidade são estabelecidos pelo menor valor de cada característica que o cliente está disposto a aceitar sem levar em conta as outras características. Por exemplo, abaixo de certo nível de qualidade, poucos clientes estarão propensos a comprar um produto, independentemente de seu preço ou das funções que pode desempenhar. O preço máximo é determinado pelo valor máximo que o cliente se dispõe a pagar, e o preço mínimo está atrelado aos custos acrescidos da margem de lucros (COOPER; SLAGMULDER, 1997; 1999).

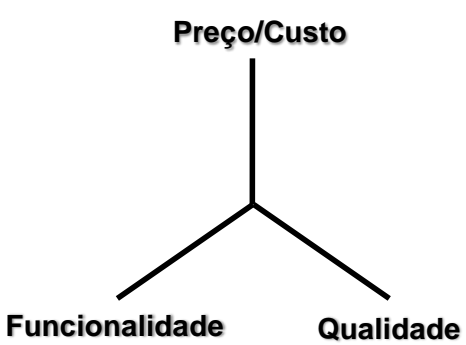

(a)

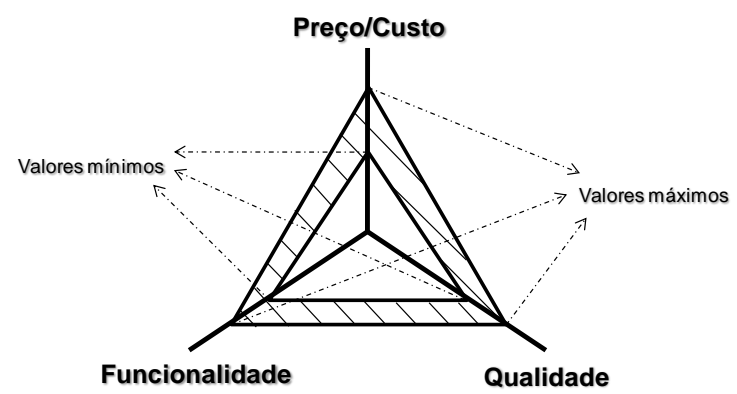

(b)

Fonte: Extraídos de Cooper e Slagmulder (1997)

Figura 3 - (a) Tripé de sobrevivência e (b) zona de sobrevivência

\begin{tabular}{|l|l|l|}
\hline \multicolumn{2}{|c|}{ Mínimo } & Máximo \\
\hline Preço & Custos acrescidos da margem de lucros & $\begin{array}{l}\text { Valor máximo que o cliente se dispõe a } \\
\text { pagar }\end{array}$ \\
\hline Qualidade & $\begin{array}{l}\text { Menor valor que o cliente está disposto a } \\
\text { aceitar sem levar em conta as outras } \\
\text { características }\end{array}$ & $\begin{array}{l}\text { Valor mais alto que a empresa pode } \\
\text { suportar sem comprometer as outras } \\
\text { características }\end{array}$ \\
\hline
\end{tabular}

Fonte: Baseado em Cooper e Slagmulder (1997)

Quadro 1 - Valores mínimos e máximos do tripé de sobrevivência 
Dessa forma, o primeiro estágio numa aplicação da abordagem custeio-meta ao PDP é a determinação do padrão mínimo de qualidade e funcionalidade que um produto deve contemplar para ser aceito pelo cliente e o preço máximo que ele se dispõe a pagar (Figura 2, parte 1). No caso de uma aplicação no contexto de edificações, nessa etapa já devem estar definidos o local, a finalidade da edificação (comercial, residencial, etc.), o padrão (de interesse social, classe econômica, média, etc.), o conceito (condomínio clube, "verde", etc.), o número de unidades habitacionais que farão parte da edificação e demais características que podem influenciar substancialmente o preço de venda. Uma pesquisa junto aos clientes em potencial e corretores que atuam na região onde o empreendimento será desenvolvido pode apontar itens que agregam valor adicional desejado ao produto. A partir daí, têm-se pelo menos duas opções para a determinação do preço de venda:

(a) através de conhecimento de mercado (Figura 2, partes 2 e 4) - com informações colhidas de corretoras de imóveis, de produtos concorrentes e de produtos desenvolvidos anteriormente pela empresa - aliado a estudos preliminares, como estudos de massa e quadro de áreas; ou

(b) através de sistemas estratégicos de informação aliados ao conhecimento de mercado (Figura 2, parte 3 e 5) (JACOMIT; GRANJA; PICCHI, 2008).

A utilização desses sistemas requer o desmembramento dos requisitos dos clientes em atributos de projeto. Esses desmembramentos servirão de base também para a determinação da primeira estimativa do custo de produção $(\mathrm{CP})$ (Figura 2, partes 11 e 12). Os sistemas estratégicos de informações (Figura 2, entre as partes 3 e 5) devem ser capazes de converter o valor acrescentado ao produto por cada atributo de projeto em preço (NICOLINI et al., 2000).

Conhecendo-se o preço de mercado (PM) e estabelecendo-se a margem de lucro desejada, o custo permissível (CPer) é determinado (Figura 2, partes 8 e 9) $(\mathrm{CPer}=\mathrm{PM}-$ lucro $)$. Na maioria das vezes, o custo permissível é impossível de ser alcançado com as capacidades produtivas atuais da empresa em questão. Dessa forma, os gerentes de cada parte do projeto e de suprimentos são convocados para estabelecer quais são as reais capacidades de redução de custos de cada área, estabelecendo, assim, o custo-meta (CM) (CPer < $\mathrm{CM}>\mathrm{CP} 1$ ) (Figura 2, parte 10). Paralelamente a esse processo de determinação do custo-meta, fazse uma primeira estimativa para o custo de produção (CP) mediante a comparação das características do produto (como padrão, localização, atributos de projeto) com dados históricos de obras executadas anteriormente pela empresa (Figura 2, partes 11 e 12). O Quadro 2 mostra um resumo dos diferentes conceitos empregados que envolvem a palavra "custo".

Normalmente, a primeira estimativa para o custo de produção é superior custo-meta $(\mathrm{CP}>\mathrm{CM})$ (Figura 2, partes 13). Então, inicia-se um processo de recalcular ou reavaliar os modelos até que se obtenha um custo de produção menor ou igual ao custo-meta $(\mathrm{CP} \leq \mathrm{CM})$, ou seja, até que se tenha um produto rentável, que o mercado deseje e com o preço que ele possa pagar (JACOMIT; GRANJA; PICCHI, 2007). Para isso, é necessário o emprego de conceitos de engenharia de valor, como análises funcionais (AF) e workshops, e de um sistema interorganizacional de gerenciamento de custos (NICOLINI et al., 2000). Esse sistema deve ser capaz de desmembrar o custo-meta de um produto em seus sistemas funcionais, subsistemas e componentes (Figura 2, parte 14). Nessa fase, que coincide aproximadamente com a conclusão do anteprojeto, o nível de incerteza já é menor em relação àquele no qual foi determinada a primeira estimativa do CP. Dessa forma, à medida que as informações de projeto se tornam disponíveis, é possível elaborar versões mais precisas do orçamento, que irão determinar as novas estimativas do CP.

\begin{tabular}{|l|l|}
\hline $\begin{array}{l}\text { Custo permissível (CPer) } \\
\text { (Allowable Cost) }\end{array}$ & CPer = Preço de mercado - Lucro unitário \\
\hline $\begin{array}{l}\text { Primeira estimativa do Custo de } \\
\text { Produção (CP1) } \\
\text { Drifting Cost) }\end{array}$ & $\begin{array}{l}\text { Baseado em dados históricos ou referenciais de } \\
\text { mercado, como o CUB por exemplo }\end{array}$ \\
\hline $\begin{array}{l}\text { Custo-meta (CM) (nível de produto) } \\
\text { (Target Cost) }\end{array}$ & $\begin{array}{l}\text { CPer < CM < CP1 } \\
\text { Leva em consideração as reais capacidades de } \\
\text { redução de custos da empresa }\end{array}$ \\
\hline $\begin{array}{l}\text { Demais estimativas do custo de } \\
\text { produção (CP2) - Orçamento }\end{array}$ & $\begin{array}{l}\text { Baseado no CP1 e nos dados de projeto } \\
\text { (O orçamento vai sendo refinado à medida que as } \\
\text { informações se tornam disponíveis) }\end{array}$ \\
\hline $\begin{array}{l}\text { Custo-meta ao nível de sistemas ou } \\
\text { componente }\end{array}$ & $\begin{array}{l}\text { Desdobramento do custo-meta (nível de produto) } \\
\text { (Estratégia top-down) }\end{array}$ \\
\hline CP ao nível de sistemas & $\begin{array}{l}\text { Soma dos custos unitários de cada componente } \\
\text { (Estratégia botton-up) }\end{array}$ \\
\hline CP ao nível de componente & Custo unitário de cada componente \\
\hline
\end{tabular}

Quadro 2 - Diferentes conceitos adotados que envolvem a palavra custo 
Com isso, é possível determinar o cost gap ou "lacuna entre custos" ( cost gap $=\mathrm{CM}-\mathrm{CP})$, ou seja, em quanto o custo de produção tem de ser reduzido para se atingir o custo-meta (NICOLINI et al., 2000) (Figura 2, parte 15). Consequentemente, pode-se também identificar quais são os componentes que representam maior peso no custo, principalmente aqueles que possuem maior lacuna entre custos, ou seja, têm maior potencial para serem reduzidos e devem ser analisados a fundo (Figura 2, parte 15). A partir desse ponto, surge a necessidade do envolvimento da cadeia de suprimentos (por isso o sistema de gerenciamento de custos é chamado de interorganizacional). É necessário o comprometimento dos fornecedores/prestadores de serviços-chave em aperfeiçoar seus próprios processos produtivos, para que os custos do componente e, consequentemente, do produto possam baixar.

$\mathrm{Na}$ manufatura, para que esse aperfeiçoamento ocorra, produtores e fornecedores/prestadores de serviços trabalham em cooperação e adotam uma prática aberta de preços (open book ou livro aberto), ou seja, o produtor tem acesso ao processo produtivo, sistema de custos e política de preços do fornecedor (Figura 2, parte 17). Com isso, o fornecedor implantará também o custeio-meta dentro de seu próprio processo produtivo. Então, inicia-se um processo de engenharia de valor contínuo até que se obtenha o produto com os atributos certos ao preço que se espera que o mercado vá absorver, ou seja, entra-se num ciclo descrito pelas partes 13 a 18 do fluxograma da Figura 2, até que se atinja o custo-meta ( $\mathrm{CP} \leq$ $\mathrm{CM}$ ). Só então o projeto é finalizado e o produto pode ser fabricado, iniciando-se um processo de melhoria contínua, chamado custeio-kaizen, em que metas de redução de custos são estabelecidas para cada departamento ou parte da linha de montagem, a fim de se continuar a redução de custos e de aumentar o valor agregado ao produto (ver Figura 2, partes 16 e 17).

A Figura 2 sintetiza as principais partes da abordagem custeio-meta ao processo de desenvolvimento de produto ${ }^{6}$ segundo Cooper e Slagmulder (1997). Entretanto, essas partes podem ganhar ou perder ênfase, podendo alguns dos processos envolvidos (itens) chegar a ser suprimidos, de acordo com alguns fatores que refletem a estratégia adotada por cada indústria e por cada empresa em particular. Cooper e Slagmulder (1997) identificaram alguns fatores que influenciam a aplicabilidade do custeio-meta a partir de uma análise de empresas de manufatura que utilizavam essa estratégia no desenvolvimento de seus produtos. Esses fatores serão apresentados a seguir.

\section{Fatores que influenciam a aplicação do custeio-meta na manufatura}

A partir de estudos de caso conduzidos na manufatura japonesa, Cooper e Slagmulder (1997) inferiram fatores que influenciam uma aplicação de custeio-meta, ou seja, o PDP com a aplicação de custeio-meta é diferente de empresa para empresa, em resposta a alguns fatores. Dessa forma, o custeio-meta não pode ser descrito como uma abordagem única e imutável - ela deve ser adaptada de acordo com as condições às quais a instituição ou a empresa estão sujeitas. De acordo com Cooper e Slagmulder (1997), esses fatores são:

(a) intensidade de competição: quanto maior, menor a zona de sobrevivência;

(b) sofisticação dos clientes (quanto à capacidade de detectar diferenças entre produtos concorrentes com relação ao preço, funcionalidade e qualidade): quanto maior, menor a zona de sobrevivência;

(c) frequência com que as exigências dos clientes mudam: quanto maior, menor é a previsibilidade da localização da zona de sobrevivência;

(d) grau de entendimento sobre os requisitos futuros do produto: quanto maior, maior é a previsibilidade da localização da zona de sobrevivência;

(e) variedade de produtos sendo produzidos: quanto maior, maior é o investimento necessário no PDP;

(f) frequência de lançamentos de modelos revisados/atualizados: quanto maior, maior é o investimento necessário no PDP;

(g) grau de inovação do produto: quanto maior, (i) menor é a previsibilidade da localização da zona de sobrevivência, (ii) maior é o investimento necessário no PDP, (iii) menor é a previsibilidade do custo do produto e (iv) menor é a previsibilidade do custo dos componentes;

(h) complexidade do produto: quanto maior, (i) maior é o investimento necessário no PDP, (ii) menor é a previsibilidade do custo do produto e (iii) menor é a previsibilidade do custo dos componentes;

\footnotetext{
${ }^{6}$ Uma descrição mais detalhada de todo o processo, item a item, pode ser encontrada em Jacomit, Granja e Picchi (2007).
} 
(i) investimento inicial necessário para se produzir: quanto maior, maior é o investimento necessário no PDP;

(j) duração da fase de desenvolvimento de produto: quanto maior, (i) menor é a previsibilidade da localização da zona de sobrevivência, (ii) menor é a previsibilidade do custo do produto e (iii) maior é a previsibilidade do custo dos componentes;

(k) grau de integração horizontal (nível de terceirização dos produtos e serviços consumidos na fabricação de um produto): quanto maior, maior é a magnitude do orçamento referente a produtos adquiridos de fontes externas;

(l) influência sobre os fornecedores: quanto maior, maior é a previsibilidade do custo dos componentes; e

(m) relação entre produtor (comprador) e sua cadeia de suprimentos: quanto maior, maior é a previsibilidade do custo dos componentes.

\section{Método de pesquisa}

Segundo trabalho desenvolvido por Ansari, Bell e Okano (2007), a variedade de tópicos abordados numa linha de pesquisa varia de acordo com a maturidade dessa linha, partindo da conceituação e inferência lógica de constructos e hipóteses, e evoluindo até a fase de teste de constructos e proposições. Esses autores concluíram que a linha de pesquisa na qual o custeio-meta está incluído está ainda num estágio inicial de maturação. Isso quer dizer que, nesses estágios, a formulação de hipóteses e relacionamento entre variáveis se torna particularmente desafiadora, visto que, em muitos casos, os constructos e/ou variáveis ainda não são conhecidos suficientemente. Com base nisso, este artigo almeja contribuir para a geração de teoria sobre a abordagem custeio-meta tomando como base um contexto específico de análise a partir de estudo de caso exploratório.

A estratégia de pesquisa adotada partiu da seleção das características dos EHIS que podem causar maior interferência no PDP com aplicação do custeio-meta. A inferência sobre como e por que essas características podem influenciar a aplicabilidade do custeio-meta foi possível mediante o confronto das informações coletadas na revisão da literatura, principalmente aquelas sintetizadas na Figura 2, com os dados e evidências coletados ao longo do estudo de caso.

O desenvolvimento da teoria seguiu as recomendações de Whetten (1989) sobre o que constitui uma contribuição teórica. Segundo o autor, a fundamentação de uma teoria é constituída da resposta às questões "o quê", "como", "por quê" e "quem, onde e quando". "O quê" descreve quais fatores (variáveis, constructos ou conceitos) logicamente devem ser considerados para explicar o fenômeno de interesse. O elemento "como" objetiva conectar e ordenar os fatores, muitas vezes indicando relações de causa e efeito. O elemento "por quê" é a justificativa para a escolha desses fatores e de seu relacionamento. "Quem, onde e quando" descrevem as limitações da teoria proposta. O Quadro 3 descreve quais são as contribuições deste artigo para o desenvolvimento da teoria sobre custeio-meta no desenvolvimento de EHIS.

O estudo de caso exploratório foi desenvolvido em uma companhia habitacional pública que atua no Estado de São Paulo e executa programas habitacionais voltados para a população de baixa renda. As fontes de evidências utilizadas foram:

\begin{tabular}{|c|c|}
\hline$O q u \hat{e}$ & $\begin{array}{l}\text { Identificação e seleção das características dos EHIS que potencialmente podem } \\
\text { influenciar a aplicabilidade do custeio-meta no contexto analisado }\end{array}$ \\
\hline Como & $\begin{array}{l}\text { Como estas características interferem no custeio-meta (esta análise é apresentada } \\
\text { em um quadro específico (Quadro 4), introduzido posteriormente) }\end{array}$ \\
\hline Por quê & $\begin{array}{l}\text { Por que as características analisadas podem influenciar a aplicabilidade do } \\
\text { custeio-meta no contexto analisado (esta análise é apresentada em uma sessão } \\
\text { específica, introduzida posteriormente) }\end{array}$ \\
\hline $\begin{array}{l}\text { Quem, onde e } \\
\text { quando }\end{array}$ & $\begin{array}{l}\text { Verificou-se, durante a condução da pesquisa, que muitas das características } \\
\text { analisadas não são específicas dos EHIS; elas também são típicas de outros tipos } \\
\text { de empreendimentos do subsetor de edificações. Entretanto, no âmbito desta } \\
\text { pesquisa, as análises foram realizadas supondo-se a aplicação do custeio-meta por } \\
\text { uma companhia de provisão habitacional. }\end{array}$ \\
\hline
\end{tabular}

Quadro 3 - Desenvolvimento da teoria subjacente ao estudo da interferência das características dos EHIS na aplicabilidade do custeio-meta 
(a) entrevistas semiestruturadas com responsável da área de orçamentos da companhia de provisão habitacional analisada e da área de projetos pessoalmente e por email;

(b) análise de documentos (plantas, memoriais, planilha orçamentária, contratos, termos de referência);

(c) reuniões com a presença de representante da companhia habitacional; e

(d) pesquisa no sítio da companhia na internet.

A coleta de dados ocorreu durante o período aproximado de 1 ano. Os dados foram coletados de modo que eles permitissem a triangulação dos dados, ou seja, tendo em vista a corroboração do mesmo fenômeno (YIN, 2005). Dessa forma, a análise das inferências sobre a aplicabilidade do custeio-meta em EHIS não decorreu de um processo padronizado isolado, ou seja, não é possível, por exemplo, vincular determinada inferência com dada questão do questionário aplicado em uma entrevista.

\section{0 processo de desenvolvimento de EHIS}

O fluxograma da Figura 4 apresenta os principais passos no desenvolvimento de um EHIS sob o regime de contratação por empreitada global, de acordo com levantamento realizado na companhia de provisão habitacional estudada. A companhia estudada já atuou no desenvolvimento ou financiamento de 439.161 unidades habitacionais ${ }^{7}$, sob os mais diversos regimes de contratação e de execução, como, por exemplo, autoconstrução, mutirão, administração direta, cartas de crédito, empreitada global e integral.

A implementação de um programa de habitação de interesse social se inicia com a identificação da demanda por esse tipo de habitação em determinada região do estado e pela determinação da solução de atendimento da demanda. A demanda é caracterizada por famílias residentes no município em questão, não proprietárias de imóveis e com renda entre 1 e 10 salários mínimos. Para a escolha da solução de atendimento há grande variedade de opções, como as descritas acima, entre elas a opção por empreitada global. Nessa opção, a prefeitura municipal é envolvida e será responsável pela doação do terreno e pela execução das obras de infraestrutura urbana. O promotor financeiro será a companhia habitacional.
A partir daí a companhia habitacional inicia seu processo de análise interna do empreendimento, com a identificação das necessidades dos futuros usuários e a definição de metas para o empreendimento, como o número de unidades habitacionais a serem construídas e a destinação de verbas. Em geral, é contratada, então, a empresa que fará o levantamento topográfico e as sondagens no terreno para a elaboração do projeto de fundações. Após essa etapa, a companhia elabora 0 termo de referência (TR) para contratação de projetos completos e serviços de aprovação que oferece diretrizes gerais para auxiliar na elaboração do projeto por empresa terceirizada, junto com o manual técnico de projetos.

Após a aceitação dos projetos pela companhia, o orçamento básico é elaborado e, após sua aprovação, inicia-se o processo licitatório para a execução das obras. No processo licitatório para o regime de execução de empreitada a preço global, o valor global de referência é determinado pelo orçamento elaborado pela companhia habitacional. A empresa vencedora da licitação será aquela que apresentar o maior desconto em relação a esse preço, não podendo o desconto ser superior a $25 \%$ do preço global de referência. No decorrer da execução da obra, ocorre o cadastro das famílias candidatas e a realização de sorteio para a determinação dos futuros mutuários. As unidades habitacionais são então comercializadas e entregues a seus moradores, após a aceitação das obras pela companhia habitacional.

Para ajudar a garantir a qualidade das unidades entregues em EHIS, o governo do Estado de São Paulo criou o Programa da Qualidade da Construção Habitacional do Estado de São Paulo (QualiHab), que é adotado pela companhia estudada. O Programa está estruturado por uma Coordenação Geral e uma Secretaria Executiva, que coordenam três comitês:

(a) o Comitê de Projetos e Obras, que congrega as entidades representativas das empresas de construção e projetos;

(b) o Comitê de Materiais, Componentes e Sistemas Construtivos, que congrega as entidades dos produtores de insumos para as obras e de sistemas construtivos; $\mathrm{e}$

(c) o Comitê Interno, encarregado de implantar um sistema de gestão da qualidade na companhia habitacional.

\footnotetext{
${ }^{7}$ Dados da companhia habitacional, estudada até dezembro de 2008.
} 


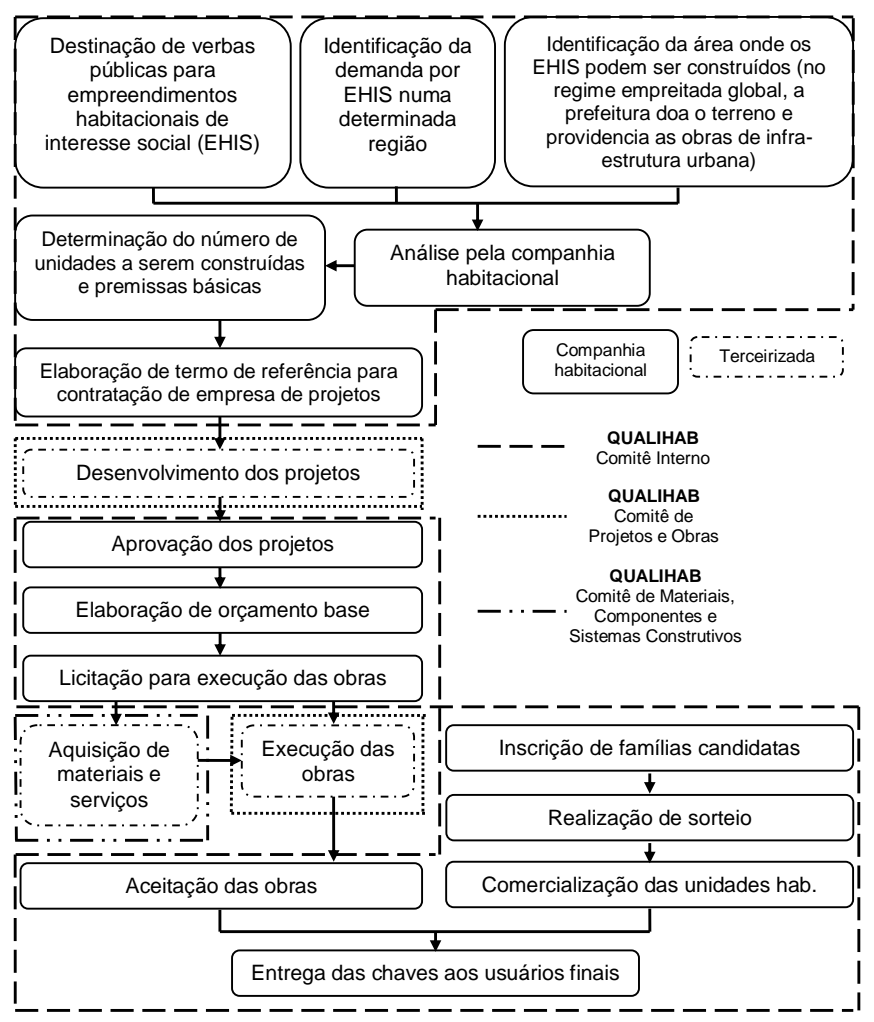

Figura 4 - Desenvolvimento de EHIS em regime de contratação por empreitada global

A vinculação ao programa QualiHab ocorre por meio de acordos setoriais com entidades representativas dos diversos setores da construção. Depois de firmado esse acordo, a entidade participante deve assumir o compromisso de desenvolver os programas setoriais da qualidade (PSQ) junto às empresas que representam. Para estimular as empresas a participarem do Programa, os requisitos do PSQ (divididos em níveis de qualificação) são exigidos nos contratos da companhia habitacional, em conformidade ao cronograma estabelecido no PSQ.

\section{Características dos EHIS que influenciam a aplicabilidade do custeio-meta}

Como discutido anteriormente, o objetivo deste artigo é inferir como e por que algumas características dos EHIS - a maioria delas comuns também a muitos empreendimentos do subsetor de edificações e da construção civil como um todo influenciam a aplicabilidade do custeio-meta. Assim seria possível antever oportunidades e dificuldades de implementação no contexto de análise e também quais seriam as possibilidades para contornar as dificuldades apresentadas. Por exemplo, se a baixa colaboração está anulando as oportunidades para redução de custos por causa dos fornecedores, pode-se tomar medidas para aumentar a colaboração, como a adoção de contratos de incentivo.

Como o custeio-meta representa uma nova forma de desenvolver produtos, uma implementação do custeio-meta no contexto de EHIS traria mais benefícios se ela fosse realizada na empresa que desenvolve os produtos, no caso a companhia de provisão habitacional ${ }^{8}$. Dessa forma, as análises dos dados provenientes do estudo de caso foram realizadas considerando-se uma possível aplicação do custeio-meta pela companhia habitacional.

As características a serem analisadas foram selecionadas buscando-se aquelas que poderiam causar maior interferência no PDP com aplicação do custeio-meta. A inferência sobre como e por que essas características podem influenciar a aplicabilidade do custeio-meta foi possível por meio do confronto das informações coletadas na revisão da literatura, principalmente aquelas sintetizadas na Figura 2, com os dados e evidências coletados ao longo do estudo de caso. As características analisadas são indicadas na coluna 1 do Quadro 4.

\footnotetext{
${ }^{8}$ Com exceção dos casos em que o governo ou a companhia habitacional contrata uma empresa por empreitada integral, ou seja, para a elaboração completa do empreendimento, como no caso dos empreendimentos elaborados a partir do programa do Governo Federal "Minha casa, minha vida".
} 


\begin{tabular}{|c|c|c|}
\hline Característica & Interferência no custeio-meta & $\begin{array}{l}\text { Parte da Figura } \\
2 \text { influenciada }\end{array}$ \\
\hline $\begin{array}{l}\text { Empresa sem fins } \\
\text { lucrativos }\end{array}$ & $\begin{array}{l}\text { Devido a inexistência de margem de lucros para ser gerenciada, o custo permissível } \\
\text { terá de ser determinado com base em critérios diferentes da margem de lucros e do } \\
\text { preço }\end{array}$ & Parte 1 a 9 \\
\hline \multirow{2}{*}{$\begin{array}{l}\text { Elaboração da } \\
\text { primeira estimativa de } \\
\text { custos após o } \\
\text { desenvolvimento do } \\
\text { projeto }\end{array}$} & $\begin{array}{l}\text { Quanto mais tarde iniciar o processo de estimativa dos custos de produção, mais } \\
\text { tarde poderão iniciar as análises de valor }\end{array}$ & Parte 14 a 18 \\
\hline & $\begin{array}{l}\text { Se o processo de estimativa dos custos de produção iniciar após a realização do } \\
\text { projeto, não será possível o gerenciamento proativo dos custos (consideração do } \\
\text { custo como parâmetro de entrada para o projeto) }\end{array}$ & $\begin{array}{l}\text { Todo o } \\
\text { processo }\end{array}$ \\
\hline \multirow{3}{*}{$\begin{array}{l}\text { Existência de } \\
\text { processo licitatório } \\
\text { para a execução da } \\
\text { obra (contratado } \\
\text { único) }\end{array}$} & $\begin{array}{l}\text { Ocorre o favorecimento da utilização de composições padrões de custos que podem } \\
\text { não representar a realidade construtiva, comprometendo o processo de } \\
\text { determinação do custo de produção (a partir da segunda estimativa) }\end{array}$ & Parte 14 a 18 \\
\hline & $\begin{array}{l}\text { Impede que a construtora participe do processo de projeto e dos workshops, } \\
\text { podendo comprometer a 'construtibilidade' do empreendimento e o processo de } \\
\text { redução de custos. }\end{array}$ & \multirow[t]{2}{*}{ Parte 14 a 18} \\
\hline & Diminui/anula a redução de custos proveniente de negociações com fornecedores & \\
\hline $\begin{array}{l}\text { Processo de } \\
\text { elaboração do projeto } \\
\text { terceirizado }\end{array}$ & $\begin{array}{l}\text { Aumenta a complexidade das análises de valor ou do processo de consideração do } \\
\text { impacto de cada alteração de projeto no custo do empreendimento }\end{array}$ & Parte 14 a 18 \\
\hline \multirow{2}{*}{$\begin{array}{l}\text { Forma de } \\
\text { remuneração do } \\
\text { projeto por preço } \\
\text { fechado ou por m² }\end{array}$} & $\begin{array}{l}\text { Não recompensa esforços da equipe de projetos na busca de inovações que visem } \\
\text { à redução de custos e/ou aumento da qualidade e/ou funcionalidade }\end{array}$ & \multirow[b]{2}{*}{ Parte 14 a 18} \\
\hline & $\begin{array}{l}\text { Com contratos de incentivo, o escritório de projetos pode ser motivado a buscar } \\
\text { soluções criativas, inovações, que visem à redução de custos e/ou aumento da } \\
\text { qualidade e/ou funcionalidade }\end{array}$ & \\
\hline "Cliente não usuário" & $\begin{array}{l}\text { Diminui a importância dos custos de manutenção (energia, água, reparos, etc.) da } \\
\text { edificação e, com isso, também perde importância a aplicação de custeio-meta com } \\
\text { a consideração dos custos ao longo do ciclo de vida (life cycle costs). Influencia } \\
\text { principalmente no estabelecimento do custo-permissível e nas análises de valor. }\end{array}$ & $\begin{array}{l}\text { Todo o } \\
\text { processo }\end{array}$ \\
\hline $\begin{array}{l}\text { Usuários não } \\
\text { incluídos no processo } \\
\text { de projeto }\end{array}$ & $\begin{array}{l}\text { Diminui a consideração das necessidades específicas dos usuários na elaboração } \\
\text { do projeto, aumentando a necessidade de pesquisas de mercado ou troca de } \\
\text { informações com a área de vendas }\end{array}$ & \multirow{2}{*}{$\begin{array}{l}\text { Parte } 1 \text { a } 9 \\
\text { ganham ênfase }\end{array}$} \\
\hline \multirow{3}{*}{$\begin{array}{l}\text { Alto nível de } \\
\text { padronização do } \\
\text { projeto ( } v s . \\
\text { personalização) }\end{array}$} & $\begin{array}{l}\text { Quanto mais alto, menor a consideração das necessidades específicas dos usuários } \\
\text { na elaboração do projeto, aumentando a necessidade de pesquisas de mercado ou } \\
\text { troca de informações a área de vendas }\end{array}$ & \\
\hline & $\begin{array}{l}\text { Quanto mais alto, menor a disparidade entre os preços e características de produtos } \\
\text { similares - maior facilidade de se determinar o preço de mercado, o custo } \\
\text { permissível e a primeira estimativa do custo de produção }\end{array}$ & \multirow{4}{*}{ Partes 1 a 18} \\
\hline & $\begin{array}{l}\text { Quando a padronização é baixa, aumenta a consideração das necessidades } \\
\text { específicas dos usuários, diminuindo a necessidade de pesquisas de mercado e } \\
\text { aumenta substancialmente a dificuldade de se determinar o preço de mercado, o } \\
\text { custo permissível e a primeira estimativa do custo de produção }\end{array}$ & \\
\hline \multirow{5}{*}{$\begin{array}{l}\text { Alta repetitividade do } \\
\text { projeto (utilização de } \\
\text { um mesmo projeto em } \\
\text { mais de um } \\
\text { empreendimento) }\end{array}$} & $\begin{array}{l}\text { Quanto maior a 'repetitividade', maior a confiabilidade na determinação do custo } \\
\text { permissível, custo-meta e do custo de produção }\end{array}$ & \\
\hline & Quanto maior, maior a importância da fase de desenvolvimento de produto & \\
\hline & $\begin{array}{l}\text { Quanto maior, aumentam as oportunidades de redução de custos na fase de } \\
\text { construção, principalmente se a mão-de-obra for mantida constante }\end{array}$ & $\begin{array}{l}\text { Entre as partes } \\
19 \text { e } 20 \\
\end{array}$ \\
\hline & $\begin{array}{l}\text { Quanto maior, maior a probabilidade de que haja feedback dos usuários, permitindo } \\
\text { que sejam identificadas oportunidades para redução de custos e/ou aumento da } \\
\text { qualidade e/ou funcionalidade ou adequação dos níveis de funcionalidade e } \\
\text { qualidade mínimos pré-estabelecidos }\end{array}$ & \\
\hline & $\begin{array}{l}\text { Quando a 'repetitividade' é baixa, aumenta a complexidade do custeio-meta, } \\
\text { principalmente na determinação do custo-meta e da primeira estimativa do custo de } \\
\text { produção }\end{array}$ & \\
\hline \multirow{2}{*}{$\begin{array}{l}\text { Baixo nível de } \\
\text { utilização de peças } \\
\text { pré-fabricadas } \\
\text { (construção vs. } \\
\text { montagem) }\end{array}$} & $\begin{array}{l}\text { Aumenta a complexidade do custeio-meta, principalmente o gerenciamento inter- } \\
\text { organizacional dos custos }\end{array}$ & \\
\hline & $\begin{array}{l}\text { Quanto maior, mais próximo o contexto de análise do contexto da manufatura e } \\
\text { maior a probabilidade de estabelecimento de relacionamento de parceria com } \\
\text { fornecedores, aumentando a probabilidade de haver redução de custos associada } \\
\text { aos fornecedores (negociação e aperfeiçoamento de processos) }\end{array}$ & Parte 14 a 18 \\
\hline \multirow{3}{*}{$\begin{array}{l}\text { Mão de obra } \\
\text { terceirizada (fase de } \\
\text { construção) }\end{array}$} & $\begin{array}{l}\text { Aumenta a dificuldade do processo de redução de custos na fase de construção } \\
\text { com aplicação de custeio-kaizen (melhoria contínua). }\end{array}$ & $\begin{array}{l}\text { Entre as partes } \\
19 \text { e } 20\end{array}$ \\
\hline & $\begin{array}{l}\text { Aumenta a dificuldade de estimar dados de produtividade e da padronização na } \\
\text { execução dos serviços, o que influencia na determinação do custo de produção }\end{array}$ & Partes 14 a 18 \\
\hline & $\begin{array}{l}\text { No caso de utilização de mão de obra própria, aumenta a precisão das estimativas } \\
\text { de produtividade com a padronização na execução dos serviços, o que influencia na } \\
\text { determinação do custo de produção. Facilita o processo de redução de custos na } \\
\text { fase de construção com aplicação de custeio-kaizen }\end{array}$ & $\begin{array}{l}\text { Partes } 14 \text { a } 18 \text { e } \\
\text { entre as partes } \\
19 \text { e } 20\end{array}$ \\
\hline \multirow{2}{*}{$\begin{array}{l}\text { Alto nível de } \\
\text { padronização dos } \\
\text { componentes (vs. } \\
\text { personalização) }\end{array}$} & $\begin{array}{l}\text { Quanto mais alto, maior a dificuldade no estabelecimento de parcerias, o que pode } \\
\text { prejudicar o processo de redução de custos }\end{array}$ & \multirow[b]{2}{*}{ Partes 14 a 18} \\
\hline & $\begin{array}{l}\text { Quando a padronização dos componentes é baixa, aumentam as possibilidades de } \\
\text { estabelecimento de relacionamentos de parceria com os fornecedores, facilitando o } \\
\text { processo de redução de custos }\end{array}$ & \\
\hline
\end{tabular}

Quadro 4 - Como as características dos EHIS influenciam a aplicabilidade do custeio-meta por uma companhia habitacional 
A análise de como cada característica selecionada pode influenciar a aplicabilidade do custeio-meta por uma companhia habitacional resultou no Quadro 4, que indica como as partes do custeiometa - ou do fluxograma da Figura 2 - podem ser influenciadas por cada uma das características analisadas.

Nos próximos itens, cada uma das inferências mostradas no Quadro 4 serão discutidas detalhadamente, de modo a explicar por que as características analisadas influenciam a aplicabilidade do custeio-meta.

\section{Empresa sem fins lucrativos}

O custeio-meta pode ser aplicado com muitos objetivos, entretanto um dos mais recorrentes é auxiliar no gerenciamento de lucros em mercados competitivos (COOPER; SLAGMULDER, 1997; MONDEN, 1995). Em EHIS não existe uma margem de lucros para ser gerenciada, já que o preço de cada unidade habitacional é equivalente ao repasse dos custos (construção, administrativos, financiamento, entre outros). Nesse contexto, o objetivo de uma aplicação de custeio-meta pode ser maximizar o valor entregue, em termos de aumento de qualidade e funcionalidade, sem aumento de custos. Para isso, seriam estabelecidos, no início do PDP, os níveis mínimos de qualidade e funcionalidade que permitissem condições adequadas de moradia e o custo máximo permissível que se poderia gastar com cada unidade habitacional.

Como não há interesse de a empresa obter lucros, o custo permissível não necessita ser determinado com base no preço de mercado, diminuindo a ênfase a ser dada às partes 1 a 9 da Figura 2. De fato, em EHIS, o custo máximo que pode ser gasto com cada unidade habitacional é determinado com base na demanda por habitações em determinada cidade e no montante total disponível para a execução de cada unidade. Como, em geral, existe uma demanda muito grande por essas habitações, o custo permissível a ser gasto com cada uma delas tende a ser muito reduzido. Adicionalmente, como a compra de cada unidade habitacional é vista quase como uma doação - a seleção dos futuros moradores é feita por sorteio -, os usuários têm pouca influência no processo de tomada de decisão, e suas necessidades, em termos de funcionalidade e qualidade das habitações, são atendidas na medida do que o custo permissível permite.

Nesse contexto, o exercício de igualar o custo estimado ao custo permissível seria improvável, a não ser promovendo-se subespecificações do produto. Para que uma aplicação de custeio-meta seja efetiva, ou seja, não resulte em subespecificações, os níveis mínimos de funcionalidade e qualidade precisam ser determinados antes da determinação do custo permissível. Assim, o custo permissível precisa ser determinado em função desses padrões mínimos.

\section{Elaboração da primeira estimativa do custo de produção após o desenvolvimento do projeto}

No custeio-meta os custos não são reduzidos aleatoriamente e sem um propósito específico - os custos de partes específicas do produto são reduzidos na proporção exata que irá permitir que o custo-meta seja atendido e, consequentemente, a margem de lucros planejada possa ser assegurada. São estabelecidas metas para cada parte do projeto, que são atendidas basicamente através de análises de valor, e para os fornecedores, que são atendidas através de negociações e aperfeiçoamento dos sistemas produtivos dos fornecedores. Quanto mais as primeiras estimativas de custos demoram a ocorrer, menos tempo sobrará para o processo de redução de custos, principalmente para o aperfeiçoamento do projeto mediante análises de valor, o que ocorre ente as partes 14 e 18 da Figura 2.

Se somente o custo-meta for conhecido, mas o custo de produção não tiver sido estimado, não se saberá exatamente em quanto o custo deverá ser reduzido, podendo prejudicar a eficácia do custeiometa. O mesmo poderá ocorrer se o custo-meta não for corretamente alocado para cada parte do projeto (fundação, cobertura, estrutura, etc.). Essa alocação deverá ser feita de maneira criteriosa, analisando-se as reais capacidades de redução de custos de cada parte, e não simplesmente dividindo-se o cost gap total ou percentual pelas partes do projeto.

Uma das principais características do PDP com a aplicação de custeio-meta é a consideração do custo como parâmetro de entrada para o processo de projeto. Dessa forma, se as primeiras estimativas de custo do produto ocorrerem após a realização do projeto, o gerenciamento proativo dos custos fica impedido, afetando todo o PDP. Numa aplicação de custeio-meta na manufatura, o custo de um novo produto é calculado da seguinte forma (COOPER; SLAGMULDER, 1997) (Equação 1):

Custo do novo produto $=$ Custo de um modelo antigo similar + Custo dos adicionais + Custo das alterações de projeto 
Dessa forma, para calcular o custo de um novo modelo sem dispor de seu projeto, as grandes empresas montadoras dispõem de sistemas avançados de custeio (cost tables), que determinam o custo do novo modelo a partir de dados históricos de outros modelos já fabricados pela empresa. $\mathrm{O}$ custo da funcionalidade adicional está relacionado, por exemplo, a um motor mais potente ou a um maior porta-malas. O custo de cada tipo de alteração no projeto é registrado e adicionado ao cálculo do novo modelo.

No mercado imobiliário, um processo semelhante a esse aplicado na manufatura é utilizado para o cálculo do custo de produção. Durante o estudo de viabilidade de um empreendimento, é realizada uma primeira estimativa do custo de produção, baseada em dados históricos e dados referenciais, como o $\mathrm{CUB}^{9}$. À medida que os projetos vão sendo desenvolvidos, o orçamento do empreendimento vai sendo atualizado.

Esse processo poderá ser agilizado com a utilização de softwares que integrem modelos CAD 3D (computer aided design em três dimensões) com o cronograma físico-financeiro da obra, como, por exemplo, o CAD 5D e o Building Information Modeling (BIM). Alternativamente, uma equipe de projeto pode ser treinada para avaliar os impactos de uma alteração de projeto no orçamento, mesmo que de forma relativamente precária. Outra solução é o acompanhamento do desenvolvimento do projeto por uma equipe responsável pelo orçamento, ou ainda essas avaliações serem realizadas durante as oficinas de projeto. Entretanto, tais soluções podem estar ainda distantes de se tornarem prática corrente, visto que muitas empresas do setor ainda têm dificuldades para realizar o planejamento de seus custos ou, até mesmo, estimativas e controle de seus custos (KERN; SOARES; FORMOSO, 2006).

\section{Existência de processo licitatório para a execução da obra (contratado único)}

Assumindo-se que a empresa a aplicar custeiometa é aquela a desenvolver o produto (companhia habitacional), a existência de processo licitatório para a execução do empreendimento reduz as oportunidades de redução de custos numa aplicação de custeio-meta, como mostrado na Figura 5. Essa figura mostra que o contexto que oferece mais oportunidades de redução de custos é aquele em que há cooperação entre o produtor e seus fornecedores.

\footnotetext{
${ }^{9}$ Custo unitário básico, publicado mensalmente pelo SindusCon.
}

No caso de haver processo licitatório, as oportunidades de redução de custos no PDP com a aplicação do custeio-meta ficam limitadas àquelas advindas do aperfeiçoamento do projeto. Isso ocorre pelo distanciamento entre a companhia habitacional e a maioria de seus fornecedores, e por não se conhecer a empresa que irá executar a obra durante a fase de planejamento e de projeto. Se a empresa construtora nem os fornecedores de partes importantes são incluídos no processo de projeto e dos workshops, os projetistas acabam tendo de tomar decisões que muitas vezes não são adequadas às características técnicas das empresas a executar o empreendimento ou às condições de execução da obra. Isso pode levar ao cálculo impreciso dos custos construtivos e ao comprometimento da "construtibilidade" do empreendimento, afetando as partes 14 a 18 da Figura 2, que são aquelas que deverão ocorrer durante a fase de projeto.

Como não se conhecem as reais capacidades produtivas da empresa que irá executar a obra, há de se utilizarem composições padrão de custos (por exemplo, $\mathrm{TCPO}^{10}$ ) na elaboração do orçamento (determinação do custo de produção) (partes 12 a 18 da Figura 2). Essas composições refletem os custos relacionados à prática usual do mercado, com todos os desperdícios associados característicos do setor. No entanto, uma empresa que busca a aplicação do custeio-meta está interessada, exatamente, em cortar esses desperdícios e racionalizar todo seu sistema produtivo.

Da mesma forma, se a empresa a desenvolver o produto não determina na fase de desenvolvimento quem irá prover os insumos, não poderá assumir nenhuma negociação prévia com fornecedores. Assim, anula-se a redução de custos que poderia ocorrer através desses fornecedores e torna-se "inefetiva" a quebra do custeio-meta em componentes que ocorre entre as partes 14 a 18 da Figura 2. 


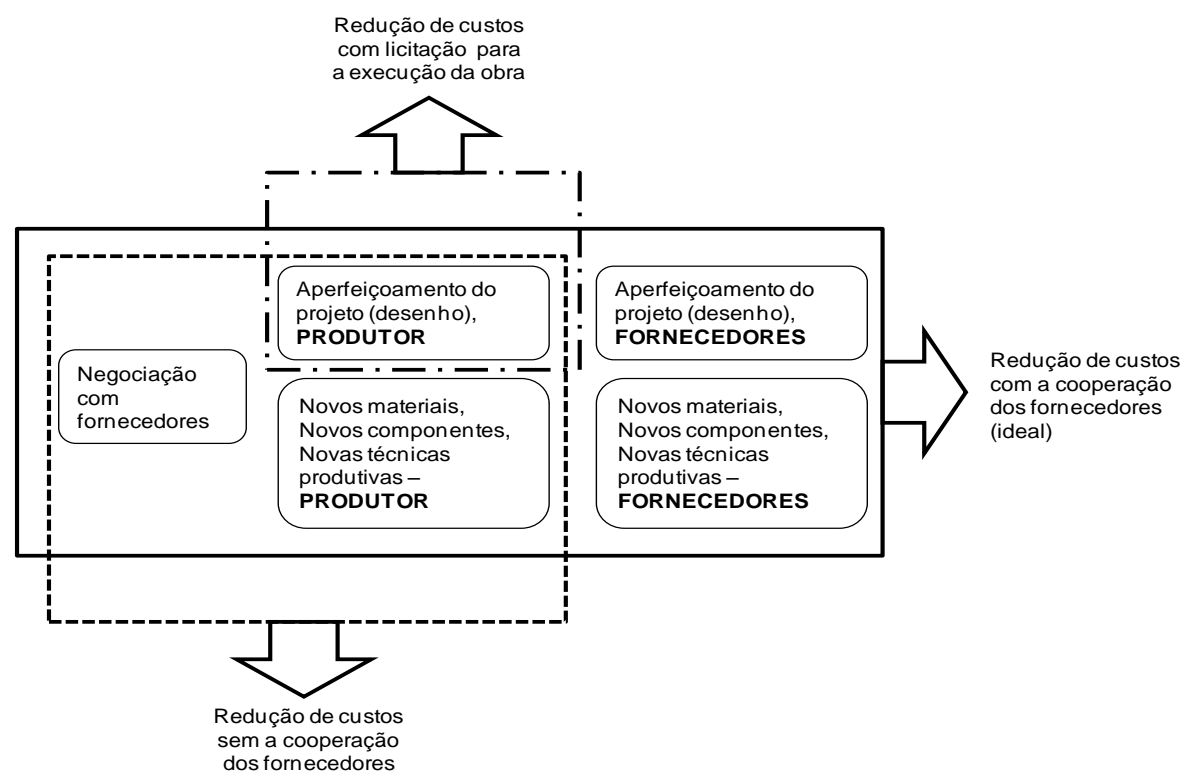

Figura 5 - Possibilidades de redução de custos com a aplicação de custeio-meta pela companhia habitacional

\section{Processo de elaboração do projeto terceirizado}

Num contexto em que o projeto é terceirizado, se a empresa a aplicar custeio-meta não é o escritório de projetos, aumentaria a complexidade da realização de análises de valor (trade-offs) e do balanceamento das dimensões custo, qualidade e funcionalidade. Eles são dificultados pela maior segmentação das informações. A companhia habitacional ou a incorporadora desenvolvem o produto com o estabelecimento de um custo máximo, que deve ser atendido. Entretanto, se o projeto é terceirizado, quem precisa se comprometer com o atendimento do custo-meta estabelecido para cada parte do projeto através de análises de valor é o escritório de projetos, atentando para os níveis mínimos de qualidade e funcionalidade estabelecidos pela empresa contratante.

No contexto específico em que a companhia habitacional está aplicando custeio-meta, ela teria de transmitir o balanceamento das dimensões custo, qualidade e funcionalidade por meio de um termo de referência (TR), documento que norteia o desenvolvimento do projeto pela contratada. Esse TR, então, teria de ser elaborado de modo a contemplar parâmetros de qualidade e funcionalidade mínimos, assim como o relacionamento desses parâmetros com o custo do empreendimento.

Esse fato dificultaria o processo de aperfeiçoamento do projeto, que ocorre entre as partes 14 e 18 da Figura 2, já que envolveria duas empresas diferentes com interesses conflitantes - companhia habitacional, ou incorporadora, e escritório de projetos. $\mathrm{O}$ escritório de projetos está interessado em reduzir ao máximo o tempo associado à elaboração de cada projeto, para minimização de seus custos; e a companhia habitacional, interessada na otimização do projeto, para redução do custo do empreendimento, o que pode representar aumento do tempo despendido com cada projeto.

Contratos de incentivo poderiam auxiliar na dissipação desses conflitos. Entretanto, para que eles sejam eficientes, é preciso que haja uma forma de medir as contribuições propostas para a melhoria do projeto ou redução de custos. Ou seja, se o escritório de projetos receberá incentivos monetários para aprimorar o projeto, é preciso que haja um mecanismo que possibilite à contratada avaliar se as modificações propostas pelo escritório de projetos representam de fato melhorias. Todavia, em geral, a efetividade dessas modificações só pode ser percebida ou avaliada na etapa de construção ou durante o uso. Essa é uma das principais dificuldades de se aplicarem contratos de incentivo na etapa de projeto.

\section{Forma de remuneração do projeto por preço fechado ou por metro quadrado}

Numa aplicação de custeio-meta na manufatura, a equipe de projeto ou de desenvolvimento de produto possui recursos financeiros e tempo para encontrar a melhor solução para o produto em termos de qualidade, funcionalidade e custo (COOPER; SLAGMULDER, 1997). Essa equipe pode lançar mão de ferramentas de engenharia de 
valor e estudar os efeitos de alterações de projeto com a elaboração de protótipos das partes novas projetadas, podendo esse processo levar de 2 a 3 anos na indústria automobilística (COOPER; SLAGMULDER, 1997).

$\mathrm{Na}$ construção civil, os recursos financeiros e o prazo são muito limitados para a elaboração dos projetos, o que dificulta que sejam estudadas soluções de projeto alternativas inovadoras. Além disso, o custo atrelado a um tempo adicional de desenvolvimento de projeto poderia tornar o projeto inviável se o produto fosse executado somente uma vez. Todavia, uma das características dos EHIS é a utilização de um mesmo projeto em mais de um empreendimento. Dessa forma, o maior investimento no desenvolvimento de projeto teria mais chances de se mostrar compensador.

Se o projeto é terceirizado e pago por preço fechado ou por metro quadrado, as oportunidades para aperfeiçoamento do projeto, que ocorrem entre as partes 14 e 18 da Figura 2, são ainda mais limitadas. Nesse contexto, não há incentivos para que o escritório de projetos invista no desenvolvimento de soluções de projeto que sejam mais adequadas às necessidades dos usuários, inovadoras, ou que visem à redução de custos. Assim, a adoção de contratos de incentivo seria premente para aumentar o comprometimento do escritório de projetos com o atendimento das necessidades dos usuários.

\section{Cliente não usuário}

Ao se tratar do estudo dos custos ao longo do ciclo de vida, é preciso definir o contexto de análise. $\mathrm{Na}$ manufatura, são realizados dois tipos de análises de custos ao longo do ciclo de vida:

(a) estudo dos custos e benefícios que irão incorrer enquanto o produto estiver sendo produzido (da concepção do produto até o produto deixar de ser produzido) (COOPER; SLAGMULDER, 1997); e

(b) estudo dos custos e benefícios que irão incorrer desde a compra até o descarte do produto pelo usuário (custos de manutenção e operação) (BARTLETT; HOWARD, 2000).

A primeira análise interessa diretamente ao produtor e é utilizada para determinar qual deveria ser a margem de lucro de um produto, levando-se em consideração também a estimativa do número de unidades a serem produzidas, a programação de vendas e o período no qual o produto será produzido. Nessa análise são considerados todos os custos associados à produção, administração, marketing, logística, suporte ao cliente e disposição final do produto, resíduos ou embalagens, caso necessário.

A segunda análise interessa ao comprador ou usuário. Assim, ela seria de especial importância no caso de haver a expectativa do cliente de um empreendimento da construção civil vir a se tornar "usuário". Por exemplo, se o cliente interessado em desenvolver um empreendimento o quiser para uso próprio (sede comercial, residência, indústria, entre outros), terá maior probabilidade de se interessar por menores custos de manutenção e melhores condições de trabalho e/ou conforto para os usuários. Nesse caso, o custo-meta deveria ser determinado com base tanto nos custos iniciais quanto nos custos ao longo do ciclo de vida. As análises de valor deveriam seguir a mesma lógica. Entretanto, a consideração dos custos ao longo do ciclo de vida aumentam substancialmente a complexidade do custeio-meta, sendo necessária a adoção de estratégias adicionais na seleção dos materiais, como aquelas descritas por Nicolini et al. (2000) e Ballard e Reiser (2004), discutidas anteriormente.

Por outro lado, se o empreendimento for concebido para venda ou locação, o cliente provavelmente terá interesse somente em custos mais baixos de construção. Todavia, é importante ressaltar que o atendimento do custo-meta não deve implicar aumento dos custos ao longo do ciclo de vida (NICOLINI et al., 2000).

\section{Usuários não incluídos no processo de projeto}

$\mathrm{Na}$ manufatura, em geral, para garantir que as necessidades dos clientes sejam atendidas e, consequentemente, o produto venda o suficiente para garantir os lucros, empresas do setor desenvolvem pesquisas de mercado, já que não costumam existir representantes dos usuários incluídos no processo de projeto. Essa é a mesma alternativa adotada por empresas da construção civil que desenvolvem empreendimentos para venda, além de realizarem reuniões com corretores de imóveis da região do empreendimento. No contexto de EHIS, como os projetos novos são muito similares, se não iguais, aos desenvolvidos anteriormente, a estratégia imediata a se adotar seria as avaliações pós-ocupação. Entretanto, como discutido anteriormente, quando as expectativas dos usuários são muito baixas, como no caso dos usuários de EHIS, essas pesquisas podem apresentar viés de satisfação, mesmo sabendo-se que as condições de moradia não são adequadas.

Quando o cliente é usuário ou quando representantes dos usuários participam do processo 
de projeto, o custeio-meta assume um foco interno, ou seja, as decisões sobre o direcionamento do PDP são tomadas internamente pela equipe de desenvolvimento em conjunto com o cliente e usuários, sem a necessidade de pesquisas de mercado, que ocorreriam entre as partes 1 e 9 da Figura 2. Quando o cliente participa do processo de projeto, algumas vezes nem mesmo o custo permissível é determinado com base no preço de mercado, como nos casos das aplicações na construção civil descritas por Ballard e Reiser (2004) e Nicolini et al. (2000).

\section{Alto nível de padronização do projeto}

Este item se refere à elaboração de projetos padronizados em relação aos concorrentes e àqueles desenvolvidos previamente pela empresa, sem personalizações que atenderiam a necessidades específicas dos usuários. Em termos gerais, quanto maior a padronização de um produto em relação a seus concorrentes, maior é o nivelamento do preço dos produtos.

Em EHIS, embora se tenha um alto grau de padronização do projeto, não há concorrentes para fazer o balizamento dos preços. Dessa forma, a determinação do custo permissível em função do preço de mercado não é a ideal. Como a empresa não visa lucros, o custo permissível deveria ser estabelecido com base no custo de produção, determinado após o estabelecimento de níveis de qualidade e funcionalidade mínimos.

Em mercados competitivos, a padronização do projeto facilita a determinação do preço de mercado e, consequentemente, do custo permissível, que ocorre entre as partes 1 e 9 da Figura 2. Em geral, um projeto padronizado deverá atender a famílias com perfis similares. Assim, são necessárias pesquisas de mercado com o públicoalvo ou troca de informações com profissionais da área de vendas, como corretoras de imóveis locais.

Já os EHIS são altamente padronizados, embora sejam desenvolvidos para o uso por famílias com perfis bastante heterogêneos. Produtos desenvolvidos para atender a perfis tão diferentes quanto famílias de mais de dois filhos e casais idosos deveriam possuir um alto grau de flexibilidade, permitindo modificações do layout interno. Pesquisas pós-ocupação, como aquelas desenvolvidas por Ornstein e Roméro (1992) e Kowaltowski et al. (2006b), seriam indispensáveis para que os empreendimentos novos pudessem evoluir continuamente e para que os erros não fossem perpetuados, considerando-se a repetição de projetos em empreendimentos novos. Dessa forma, estabelecer-se-ia um vínculo entre a percepção do usuário e a qualidade do empreendimento (KOWALTOWSKI et al., 2006a).

Em empreendimentos com alto grau de personalização, o custo permissível e o custo-meta são difíceis de determinar, já que aumenta a dificuldade de se estimar quanto o mercado pagaria pelo empreendimento. A precisão da estimativa dos custos de produção também poderia ser prejudicada, sobretudo a primeira estimativa realizada antes da realização do projeto, já que aumenta a dificuldade de encontrar empreendimentos já realizados que possam ser comparados com eles.

\section{Alta repetitividade do projeto}

Uma das possíveis argumentações contrárias à aplicação do custeio-meta na construção civil pode se basear na exclusividade de cada empreendimento. O aperfeiçoamento do projeto pode não gerar benefícios que compensem um maior investimento no desenvolvimento de um produto único. Mas a perspectiva de utilização de um mesmo projeto múltiplas vezes aumenta sua importância e a probabilidade de que seja compensador o maior investimento nessa fase do empreendimento, em que a maior parte dos custos é comprometida.

A repetição de um mesmo projeto permite a elaboração de um banco de dados de custos e de dados de produtividade, o que pode permitir que estimativas mais precisas do custo de produção sejam feitas (partes 11 a 18 da Figura 2). A possibilidade de comparação dos novos empreendimentos com outros já existentes bastante semelhantes permite maior precisão também na determinação do custo permissível (partes 1 a 9 da Figura 2). Se a empresa construtora for mantida a mesma, o custo-meta será mais preciso e poderá ser instituído mais próximo do custo permissível, já que a empresa construtora já estará habituada com a execução do produto (partes 9 e 10 da Figura 2).

A utilização de um mesmo projeto também cria a possibilidade de haver feedback dos usuários para a equipe de desenvolvimento de produtos, criando um ciclo de aperfeiçoamento do projeto. Esse feedback poderia nortear o processo de aumento de funcionalidade e qualidade do produto (partes 1 a 18 da Figura 2). Entretanto, esse aumento de funcionalidade e qualidade só se reverteria em valor para o cliente e para os usuários se ele não resultasse em aumento do preço do produto.

A alta repetitividade também aumenta a probabilidade de redução de custos na fase de 
construção com a aplicação de custeio-kaizen (melhoria contínua), se a mão de obra (terceirizada) for mantida constante (entre as partes 19 e 20 da Figura 2).

\section{Baixo nível de utilização de peças pré- fabricadas}

A utilização maciça de peças pré-fabricadas poderia aproximar o contexto de EHIS ao da manufatura. O processo de montagem de peças pré-fabricadas no canteiro permite maior agilidade e maior controle das variáveis em relação à construção convencional, em função da fabricação de partes do edifício no ambiente controlado de uma fábrica. Dessa forma, estar-se-ia menos exposto aos riscos geralmente associados à construção.

A utilização de peças pré-moldadas exige maior proximidade entre o produtor e o fornecedor, já que pode ser necessário que as peças sejam projetadas especificamente para atender às necessidades de uma obra específica. Com isso, o fornecedor torna-se mais dependente do produtor para vender determinado produto e há um alargamento da margem de negociação (partes 14 a 18 da Figura 2). A partir daí, o estabelecimento de relacionamentos de parceria seria interessante para ambos os lados. Contudo, as vantagens desse relacionamento de parceria dificilmente se reverterão à companhia habitacional se houver licitação para a execução da obra.

Quando há baixa utilização de peças préfabricadas, o gerenciamento interorganizacional dos custos se torna mais complexo, já que haverá mais componentes para ser gerenciados e produzidos na obra, aumentando as incertezas e reduzindo a precisão dos dados de custo e produtividade (partes 14 a 18 da Figura 2).

\section{Utilização de mão de obra terceirizada}

Apesar de o número de terceirizações ser relativamente alto na construção civil, a maioria delas ocorre para a prestação dos serviços, e não para fornecer partes da produto que são desenvolvidos especialmente para determinado comprador, como ocorre na manufatura. Esse tipo de terceirização dificulta a aplicação de processos contínuos de melhoria durante a execução da obra (partes 19 e 20 da Figura 2). Diminui também a precisão das estimativas de produtividade, utilizadas na determinação do custo de produção (a partir da segunda estimativa) (partes 14 a 18 da Figura 2). Entretanto, ela permite a redução dos custos quando não houver demanda e o repasse dos riscos com a execução (custos fixados previamente). A terceirização da prestação de serviços também se constitui num bom contexto para a aplicação de contratos de incentivo, como no caso descrito por Robert e Granja (2006).

\section{Alto nível de padronização dos componentes}

Numa aplicação de custeio-meta, quanto mais personalizados os componentes forem, maiores são as chances de se estabelecerem relacionamentos de parceria entre comprador e fornecedores, já que o número de compradores tende a ser reduzido, se comparado a componentes padronizados. Mas isso só ocorre se houver disponibilidade desse componente ou insumo padronizado no local em que ele será utilizado. Na construção civil, muitas vezes, materiais básicos como a areia podem ser negociados a preços abusivos para o comprador, em função da inexistência de concorrentes nas proximidades.

Quando maior o nível de personalização de um componente ou de partes do projeto, maior a tendência de que os fornecedores sejam mais dependentes do produtor e, portanto, estejam mais abertos a negociações. Também será maior a probabilidade de o produtor poder auxiliar no aperfeiçoamento do PDP do fornecedor e viceversa, já que ambos estarão desenvolvendo produtos altamente integrados (partes 14 a 18 da Figura 2).

$\mathrm{Na}$ manufatura, grande parte dos componentes fornecidos é produzida especialmente para um dado produtor ou modelo, sendo muitas vezes o projeto desse componente desenvolvido pelo produtor ou em conjunto com ele. $\mathrm{Na}$ construção civil, esse tipo de dependência é difícil de ser estabelecida, visto que empresas construtoras são, em geral, menores que fornecedores de materiais de construção (BALLARD; REISER, 2004). Estes não fornecem partes desenvolvidas especialmente para um empreendimento, mas materiais altamente padronizados. É importante ressaltar que, se houver dependência e se não houver uma aliança de negócio, as reduções de preço resultantes de negociações entre produtor e fornecedor podem resultar em comprometimento da qualidade e da funcionalidade do componente.

\section{Conclusões}

Este artigo se propôs a investigar como e por que algumas características dos EHIS - a maioria delas comuns também a outros tipos de empreendimentos do subsetor edificações - 
influenciam a aplicabilidade do custeio-meta por uma companhia habitacional. Foram analisadas 12 características dos EHIS. Para cada uma delas, realizaram-se inferências sobre como e por que elas influenciariam a aplicabilidade do custeiometa no contexto analisado.

As inferências realizadas se constituem numa contribuição teórica para o estudo da aplicabilidade do custeio-meta no contexto específico de EHIS. A análise da influência das características dos EHIS no custeio-meta permite antever possíveis dificuldades de implementação, adaptar o custeio-meta às condições do contexto de análise, concentrar esforços nas atividades mais vantajosas e/ou ajustar o contexto de análise, de modo a maximizar os benefícios e a minimizar incertezas referentes à aplicação do custeio-meta.

Algumas das características analisadas levam à diminuição dos benefícios que poderiam advir de uma aplicação de custeio-meta, como no caso da elaboração da primeira estimativa de custos após a elaboração do projeto. Outras características levam a uma aproximação do contexto de análise com o contexto da manufatura - o que pode facilitar o processo de implementação -, como no caso da utilização de um projeto em mais de um empreendimento.

Nenhuma das características de maneira isolada pode ser considerada uma barreira à aplicação do custeio-meta em EHIS por uma companhia habitacional. Entretanto, a combinação de algumas características, como:

(a) licitação da execução da obra;

(b) terceirização do projeto; e

(c) forma de remuneração que não incentiva a cooperação entre o escritório de projetos e a companhia habitacional, pode minimizar os possíveis benefícios advindos de uma aplicação de custeio-meta em EHIS.

Por outro lado, se for analisado o contexto de EHIS sob a ótica das construtoras que desenvolvem seus próprios produtos - que foram recentemente incentivadas a ingressar nesse segmento pelo programa federal "Minha Casa, Minha Vida" de existir. Esse programa pretende financiar a construção de um milhão de moradias para a população de baixa renda, sendo 400 mil dessas moradias voltadas exclusivamente para a Classe E, com renda familiar entre 0 e 3 salários mínimos (BRASIL, 2009). Com isso, a tendência é que surjam produtos alternativos àqueles

\footnotetext{
${ }^{11}$ Programa Minha Casa, Minha Vida. Disponível em: <http://www.minhacasaminhavida.gov.br/>. Acesso em: 02 out. 2009.
}

desenvolvidos tradicionalmente por companhias habitacionais. Com o incremento da concorrência e pressupondo-se o exercício de escolha desse perfil de usuário, como já ocorre em outros segmentos econômicos, as empresas precisarão reduzir o preço de seu produto e/ou criar mecanismos para se diferenciar, o que pode resultar no aumento dos níveis de qualidade e de funcionalidade dos EHIS.

A intensificação do setor de habitações populares pode impulsionar também o desenvolvimento de novas técnicas construtivas que baixem os custos produtivos e aumentem a rapidez de execução, apontando para o início de um processo de industrialização mais vigoroso na construção civil. Poderá levar também ao desenvolvimento de novas propostas de unidades, contrastando com o cenário de uniformidade de soluções atual (QUEIROZ; TRAMONTANO, 2009). Complementarmente, um ambiente de aperfeiçoamento contínuo dos produtos, com foco no mercado, é bastante propício para a aplicação do custeio-meta. Outro contexto que pode se mostrar propício para a aplicação do custeio-meta é o do Programa Arrendamento Residencial (PAR) do governo brasileiro, o qual prevê o envolvimento da companhia executora do empreendimento nas fases iniciais de sua concepção (LEAL; GUADANHIM; HIROTA, 2009). Outros tópicos de pesquisa que necessitam de aprofundamento se referem à verificação das inferências de relacionamento entre cada característica analisada dos EHIS e o custeio-meta, assim como a investigação de possíveis relacionamentos complementares.

Um dos caminhos a serem seguidos para auxiliar no aumento da qualidade dos EHIS é a melhoria da qualidade do projeto, da obra e de seus componentes, mediante a implantação de sistemas de gestão da qualidade. Um desses programas de amplo conhecimento, o QualiHab, incentiva setores da construção a instituir programas setoriais da qualidade, o que pode resultar no aperfeiçoamento das empresas e em seu melhor desempenho. Assim, as empresas estarão mais propensas a entregar produtos de qualidade, no que se refere ao atendimento às especificações. Porém, em havendo falha nas especificações, ou mesmo subespecificação dos produtos pela companhia habitacional, não se obterá o almejado incremento de satisfação dos clientes. Dessa forma, a aplicação do custeio-meta esbarraria novamente na dificuldade de se estabelecerem padrões mínimos aceitáveis de qualidade e funcionalidade para os EHIS, podendo ser as normas de desempenho (CLETO, 2006) um elemento relevante nesse âmbito. 


\section{Referências}

ANSARI, S.; BELL, J.; OKANO, H. Target Costing: uncharted research territory. In: CHAPMAN, C. S.; HOPWOOD, A. G.; SHIELDS, M. D. (Ed.). Handbook of Management Accounting Research. Oxford: Elsevier, 2007. p. 507-530.

ANSARI, S.; BELL, J.; SWENSON, D. A Template for Implementing Target Costing. Cost Management, v. 20, n. 5, set./out. 2006. p. 20.

BALLARD, G.; REISER, P. The St. Olaf College Fieldhouse Project: a case study in designing to target cost. In: ANNUAL CONFERENCE ON LEAN CONSTRUCTION, 12., 2004, Elsinore, Dinamarca. Anais... Elsinore, Dinamarca, 2004. 1 CD-ROM.

BARTLETT, E.; HOWARD, N. Informing the Decision Makers on the Cost and Value of Green Building. Building Research \& Information, Routledge, Londres, v. 28, n. 5, p. 315-324, 2000.

BRASIL. Ministério das Cidades. Minha Casa, Minha Vida. Caixa Econômica Federal, 2009, 40 p. Disponível em: <http://www.cidades.gov.br/ministerio-dascidades/arquivos-e-imagensoculto/minha_casa_minha_vida-1-1_-

_CAIXA.pdf>. Acesso em: 10 out. 2009.

CLETO, F. R. Referenciais Tecnológicos para a Construção de Edifícios. 2006. Dissertação (Mestrado em Engenharia Civil) - Escola Politécnica, Universidade de São Paulo, São Paulo, 2006.

COOPER, R.; SLAGMULDER, R. Supply chain development for the lean enterprise: portland, USA: Productivity, 1999. 512 p.

COOPER, R.; SLAGMULDER, R. Target Costing and Value Engineering, Portland, USA: Productivity Press, 1997. 379 p.

DEKKER, H.; SMIDT, P. A Survey of the Adoption and Use of Target Costing in Dutch Firms. International Journal of Production Economics, Nova York, v. 84, n. 3, p. 293-305, 2003.

DELL'ISOLA, A. P. E. Value Engineering: practical applications for design, construction, maintenance \& operations. Kingstone: RS Means, 1997.
ELLRAM, L. M. The Implementation of Target Costing in the United States: theory versus practice. Journal of Supply Chain Management: A Global Review of Purchasing and Supply, p. 1326, inverno, 2006.

FEIL, P.; YOOK, K.; KIM, I. Japanese Target Costing: a historical perspective. International Journal of Strategic Cost Management, primavera, 2004.

GRANJA, A.D. et al. Natureza do valor desejado na habitação social. Ambiente Construído, Porto Alegre, v. 9, n. 2, p. 87-103, abr./jun. 2009.

JACOMIT, A. M.; GRANJA, A. D.; PICCHI, F. A. Target Costing Research Analysis: reflections for construction industry implementation. In: ANNUAL CONFERENCE ON LEAN CONSTRUCTION, 16., 2007, Manchester, UK. Anais eletrônicos... Manchester, 2007.

KERN, A. P.; SOARES, A. C.; FORMOSO, C. T. Custo-Meta no Planejamento e Controle de Custos de Empreendimentos de Construção. In: ENCONTRO NACIONAL DE TECNOLOGIA DO AMBIENTE CONSTRUÍDO, 11., 2006, Florianópolis. Anais... Florianópolis: Antac, 2006. 1 CD-ROM.

KOWALTOWSKI, D. C. C. K. et al. Quality of Life and Sustainability Issues as Seen by the Population of Low-Income Housing in the Region of Campinas, Brazil. Habitat International, v. 30 n. 4, p. 1100-1114, 2006b.

KOWALTOWSKI, D. C. C. K. et al. Reflexão sobre Metodologias de Projeto Arquitetônico. Ambiente Construído, v. 6, n. 2, p. 7-19, abriljun. 2006a.

LEAL, J. G.; GUADANHIM, S. J.; HIROTA, E. Processo de Projeto de Habitação de Interesse Social Adequado à Abordagem Target Costing. In: LATINAMERICAN CONFERENCE ON CONSTRUCTION MANAGEMENT AND ECONOMICS, 3., 2009, Bogotá. Anais eletrônicos... Bogotá, 2009.

MICHAELS, J. V.; WOOD, W. P. Design to Cost. Wiley-Interscience, 1989. 413 p. 
MIRON, L. I. G. Gerenciamento dos Requisitos dos Clientes de Empreendimentos

Habitacionais de Interesse Social: proposta para o programa integrado entrada da cidade em Porto Alegre, RS. 2008. 351 f. Tese (Doutorado em Engenharia Civil) - Programa de Pós-Graduação em Engenharia Civil, Universidade Federal do Rio Grande do Sul, Porto Alegre, 2008.

MONDEN, Y. Target Costing and Kaizen Costing: portland, Oregon, USA: Productivity Press, 1995. 373 p.

MONDEN, Y.; SAKURAI, M. Japanese

Management Accounting. Cambridge, USA: Productivity Press, 1989. 546 p.

MORRIS, P.W.G. The Management of Projects. Londres: Thomas Telford Services, 1994. 280 p.

NICOLINI, D. et al. Can Target Costing and Whole Life Costing be Applied in the Construction Industry? Evidence from two case studies. British Journal of Management, Londres, v. 11, n. 4, p. 303-324, dez. 2000.

OKANO, H.; SUZUKI, T. A History of Japanese Management Accounting. In: CHAPMAN, C. S.; HOPWOOD, A. G.; SHIELDS, M. D. (Ed.).

Handbook of Management Accounting Research. Oxford: Elsevier, 2007. p. 1119-1137.

ORNSTEIN, S. W.; ROMÉRO, M. Avaliação Pós-Ocupação do Ambiente Construído. São Paulo: Studio Nobel, 1992.

PICCHI, F. A. Sistemas da Qualidade: uso em empresas de construção de edifícios. São Paulo: POLI-USP, 1993.
QUEIROZ, F. A. de; TRAMONTANO, M. Apartamentos Paulistanos: um olhar sobre a produção privada recente. Ambiente Construído, Porto Alegre, v. 9, n. 2, p. 139-150, abr./jun. 2009.

ROBERT, G. T.; GRANJA, A. D. Target and Kaizen Costing Implementation in Construction. In: ANNUAL CONFERENCE OF THE INTERNATIONAL GROUP FOR LEAN CONSTRUCTION, 14., 2006, Santiago, Chile. Anais... Santiago, Chile: 2006. 1 CD-ROM.

ROZENFELD, H. et al. Gestão do

Desenvolvimento de Produtos: uma referência para a melhoria do processo. São Paulo: Saraiva, 2006.

WHETTEN, D. A. What Constitutes a Theoretical Contribution? The Academy of Management Review, v. 14, n. 4, p. 490-495, out. 1989.

YIN, R. K. Estudo de Caso: planejamento e métodos. 3. ed. Porto Alegre: Bookman, 2005. 212 p.

YOOK, K.; KIM, I.; YOSHIKAWA, T. Target Costing in the Construction Industry: evidence from Japan. Construction Accounting \& Taxation, v. 15, n. 3, p. 05, maio/jun. 2005.

\section{Agradecimentos}

Os autores agradecem à Financiadora de Estudos e Projetos (FINEP), Programa Habitare, pelo apoio a esta pesquisa, e à Coordenação de Aperfeiçoamento de Pessoal de Nível Superior (CAPES), pela concessão de bolsa de pesquisa. 